\title{
BURIALS OF SUGOKLEA BARROW. PALAEOPATHOLOGICAL ASPECT OF THE STUDY ${ }^{1}$
}

\author{
Aleksandra D. Kozak \\ Institute of Archaeology National Academy of Science of Ukraine, Kyiv, Ukraine
}

\begin{abstract}
Introduction. The aim of the study is to identify the causes of differences in the diseases profile, as well as sex and age indicators of different groups of people of the Yamnaja and Babino cultures buried in Sugoklea barrow on the border of the steppe and forest-steppe areals of the Nothern Pontic region. Methods. The basic classical methods for determining the individual sex, age and body height are used in the study. In the paleopathological part the frequency of dental, metabolic and infectious diseases was evaluated. Analysis. The people of the Yamnaja culture buried in Sugoklea barrow represent a "randomly formed" group. The average age of death in men of the Yamnaja group is 45.7. In adults of the early group penetrating head injuries, traces of routine infections, and oncological diseases are determined; in children, the consequences of infections and deficient diseases caused by dietary restrictions during roaming are found. In the late group, several people show the symptoms of a latent form of tuberculous meningitis. The significant loads on the teeth (wear and tear, enamel injuries), especially after 30-40 years, the absence of caries, total calculus indicate the diet consisting of hard, unrefined, mainly protein foods. The pressure of environmental factors on the population of the Babino culture group was expressed in the high frequency of the prenatal stress markers. The number of individuals with episodic stress markers is small. Most men and women died between the age of 25 and 40 (possibly due to the negative influence of environmental factors). The complex of teeth and periodontium pathologies indicates a fibrous, proteinrich, mainly meat diet, as well as significant loads on the dental system caused by using dried fish and meat, shellfish, nuts for food. Both men and women had a high percentage of exostoses of the external ear canal along with a high incidence of middle ear diseases. This phenomenon suggests a certain dependence of the group on water resources. Results. Both groups of the Yamnaja culture are parts of the migrating nomadic population engaged in grazing or exchange. The combination of pathological signs and occupational markers allows us to consider the group of the Babino culture as cattle-breeding populations and confirm the migration theory of the origin of the syncretic funeral rite in this region.

Key words. Bronze age, Yamnaja culture, Babino culture, Northern Pontic region, paleopathology.

Citation. Kozak A.D. Burials of Sugoklea Barrow. Palaeopathological Aspect of the Study. Vestnik Volgogradskogo gosudarstvennogo universiteta. Seriya 4. Istoriya. Regionovedenie. Mezhdunarodnye otnosheniya [Science Journal of Volgograd State University. History. Area Studies. International Relations], 2020, vol. 25, no. 4, pp. 256-274. (in Russian). DOI: https://doi.org/10.15688/jvolsu4.2020.4.17
\end{abstract}

УДК 930.26(470+571):393

Дата поступления статьи: 22.03.2020

ББК 63.48(2)-427.1 Дата принятия статьи: 02.04.2020

\section{ПОГРЕБЕНИЯ КУРГАНА СУГОКЛЕЯ. ВЗГЛЯД ПАЛЕОПАТОЛОГА ${ }^{1}$}

\section{Александра Денисовна Козак}

Институт археологии Национальной академии наук Украины, г. Киев, Украина

Аннотация. Введение. Целью исследования стало выявление причин отличия в профиле заболеваний и половозрастных показателях представителей ямной и бабинской культуры, погребенных в кургане Сугоклея на границе Степи и Лесостепи понтийского региона. Mетоды. В исследовании использованы основные классические методики определения пола, возраста и роста индивидов. В палеопатологическом блоке оце- 
нивались частоты зубных, метаболических и инфекционных заболеваний. Анализ. Исследованные представители ямной культуры, погребенные в кургане Сугоклея, представляют собой «случайно» сформированную группу. Средний возраст смерти у мужчин ямной культуры 45,7 лет. У взрослых индивидов ранней группы определены проникающие травмы головы, рутинные инфекции, онкологические заболевания, у детей - последствия инфекций и дефицитных заболеваний, вызванных ограничениями в питании в процессе кочевания. В поздней группе у нескольких человек выявлены симптомы латентной формы туберкулезного менингита. Значительные нагрузки на зубы (стертость, травмы эмали), особенно после 30-40 лет, отсутствие кариеса, всеобщее поражение зубным камнем указывают на употребление жесткой, нерафинированной, преимущественно белковой пищи. Давление факторов среды на популяцию носителей культуры Бабино выразилось в высокой частоте маркеров пренатального стресса. Количество индивидов с маркерами эпизодического стресса мало. Большинство мужчин и женщин погибло в возрасте между 25 и 40 годами (влияние негативных факторов среды). Один человек дожил до старческого возраста. Комплекс изменений зубов и пародонта свидетельствует о волокнистой, богатой белком, преимущественно мясной пище и значительных нагрузках на зубную систему (употребление вяленой рыбы, мяса, моллюсков, орехов). У мужчин и у женщин обнаружен высокий процент экзостоз ушного прохода наряду с высокой частотой заболеваний среднего уха. Такое явление позволяет предположить некоторую зависимость группы от водных ресурсов. Резульmambl. Обе группы ямной культуры представляют собой части мигрировавшей кочевнической популяции, занимавшейся выпасом скота или обменом. Совокупность патологических признаков и маркеров физических нагрузок позволяет отнести группу культуры Бабино к скотоводческим популяциям и подтверждают миграционную теорию происхождения синкретического погребального обряда в этом регионе.

Ключевые слова: эпоха бронзы, ямная культура, культура Бабино, Северное Причерноморье, палеопатология.

Цитирование. Козак А. Д. Погребения кургана Сугоклея. Взгляд палеопатолога // Вестник Волгоградского государственного университета. Серия 4, История. Регионоведение. Международные отношения. 2020. - T. 25, № 4. - C. 256-274. - DOI: https://doi.org/10.15688/jvolsu4.2020.4.17

Введение. Культуры Северного Причерноморья эпохи бронзы были частью культурных сообществ евразийского континента. Крупные и мелкие племена в процессе миграций, торговли, войн вытесняли или сменяли друг друга, способствуя появлению новых групп, отличавшихся типом хозяйствования, особенностями не только культурных, но морфологических и физиологических адаптаций, генотипом и морфологическими характеристиками. Они определяли наиболее выгодные стратегии выживания в избранной ими экологической нише.

Однако в процессе выработки стратегий выживания популяции могли переживать последствия неудачных адаптаций. Последние выражались в ранней смертности от голода, острых инфекционных и метаболических заболеваний или в увеличении количества нехарактерных для сообщества травм [12].

Заболевания населения эпохи бронзы относительно мало изучены на территории Европы. В частности, исследования проводились в Германии, Австрии, Словакии [41; 54], в Балтийском регионе [6], на территории Северного Кавказа [37; 39] и Нижнего Повол- жья [21; 22]. В Украине эта тема была частично затронута С.И. Круц, рассмотревшей травмы, а также заболевания зубов и суставов у представителей ямной, катакомбной и срубной культур [14]. Подробно изучены погребения, в том числе ямной культуры, из некрополя у с. Баштечки Черкасской обл. [53]. В последние годы исследования проводятся Ю.В. Ушковой и автором данной статьи [8; $10 ; 11 ; 13 ; 30]$. Многие материалы находятся в процессе обработки. К таким относятся, например, зубные заболевания у представителей ямной, катакомбной и бабинской культур на Нижнем Днепре, травмы и трепанации у представителей населения степей Причерноморья в эпоху бронзы и т. д.

Обнаружение в одном кургане представителей двух разновременных и разнокультурных групп населения является редкой удачей и, возможно, позволит определить основные факторы, которые влияли на состояние здоровья людей, пребывавших на этой территории.

Материалы и методы. В 2011 г. на окраине Кировограда был исследован курган эпохи бронзы $[20 ; 44]$. Он располагался на мысе, образованном слиянием рек Ингулец и 


\section{БИОАРХЕОЛОГИЯ ДРЕВНИХ И СРЕДНЕВЕКОВЫХ ПОПУЛЯЦИЙ}

Сугоклея, на границе степи и лесостепи. Курган входил в группу одновременных курганов, уничтоженных во время строительства города. Здесь обнаружено 11 захоронений ямной культурной общности и 14 - культуры Бабино. Предварительные половозрастные определения были сделаны Л.В. Литвиновой сразу после открытия погребений [44]. Они были несколько уточнены в процессе подробного исследования. К сожалению, степень сохранности материала не позволила провести полноценное краниологическое исследование обеих групп. Тем не менее краниологические особенности и результаты археогенетического исследования нескольких погребений ямной культуры из кургана проанализировала И.Д. Потехина [23; 24].

Погребения ямной культуры делятся на две группы, отличающиеся временем совершения и обрядом [44].

Предварительные исследования маркеров физических нагрузок показали, что множество изменений на костях (профессиональные комплексы и их элементы) связаны с привычными занятиями мужчин группы «ямников»- стрельбой из лука, метанием копья, использованием топора, булавы или молота [11]; перенесением тяжестей на спине и в руках, длительным хождением и бегом. У двух мужчин выделен «комплекс возничего» [8]. Можно предположить, что эти люди много передвигались на повозках, части которых найдены в их погребениях. Тип и частота травм говорят о воинственном образе жизни этих людей. Травмы черепа незажившие и, очевидно, были нанесены с целью убийства [11]. Большинство травм посткраниального скелета связаны с активным образом жизни [13]. Мы предполагаем, что эта группа состоит из представителей племени (племен), занимавшихся обменом и/или кочевым скотоводством. Последнее подтверждается также и палеозоологическими определениями [31].

Что касается представителей культуры Бабино, они, вероятно, являлись небольшой локальной частью сообщества, проживавшего или пребывавшего в течение определенного отрезка времени на указанной территории. По предварительным исследованиям, травмы черепа этих людей можно охарактеризовать как бытовые. Травмы посткраниального ске- лета расположены большей частью в области стоп. Они могут расцениваться как случайные, связанные с прыжками, ходьбой по каменистой неровной или скользкой поверхности. Балансировка или передвижение по неровной поверхности, перенесение тяжестей, использование метательного оружия (копье, гарпун), гребля были основными нагрузками и занятиями этих людей. Женщины, как и самый старший мужчина, вероятно, занимались плетением сетей или ткачеством (этот материал готовится к печати). Анализ погребального обряда позволил Р.А. Литвиненко говорить о его синкретичности и о присутствии в кургане погребений одного из лесостепных вариантов культуры Бабино [15]. Интересным является факт обнаружения погребения в гробу, напоминающем «лодку» [20].

Целью этого исследования является определение и анализ основных демографических и патологических маркеров в сравнительном аспекте; обнаружение следов вероятной адаптации к среде обитания и типу хозяйствования, а также подтверждение предварительных выводов об образе жизни и мобильности этих людей.

Для исследования использованы исключительно морфологические методики. Измерения костей [1] проводились для определения основных морфологических параметров, в первую очередь длины тела [35; 47;60]. Кроме того, оценивались половозрастные характеристики, наличие и локализация травм, зубных, метаболических и инфекционных заболеваний по методикам, разработанным группой палеопатологии медицинского Университета г. Гёттинген, Германия [52; 56]. Изношенность зубов фиксировалась по методикам М.М. Герасимова для определения возраста [5] и по расширенной детализированной 13-балльной схеме В.Р.К. Перисониуса и Т.Дж. Пота [48]. Простые статистические методы (определение средних величин) применены в изучении показателей среднего возраста смерти и частот различных признаков. Обнаруженные группы погребений очень малы, это предполагает реальную возможность говорить лишь о тенденциях и в большей степени на индивидуальном, чем на популяционном уровне. В связи с этим я считаю нецелесообразным расчет достоверно- 
стей в сравнении исследуемых признаков. Следует еще раз уточнить, что обе группы не являются палеопопуляциями.

Анализ. Половозрастные определения. К ямной культуре относятся 11 погребений, среди которых 8 мужских и 3 детских. В группе, относящейся к культуре Бабино, подавляющее большинство погребений - мужские. Лишь в двух случаях мы можем с уверенностью говорить о женском поле. В одном разрушенном погребении был захоронен ребенок (табл. 1).

Тенденцию к количественному преобладанию мужских погребений в могильниках степного Поднепровья эпохи бронзы отмечала С.И. Круц. Она определила соотношение мужчин и женщин в сборной группе погребений ямной культуры как 2,3 : 1 (252 индивида), катакомбной культуры - как 2,1 : 1 (316 индивидов) и культуры многоваликовой керамики, или культуры Бабино (89 индивидов) - как $2,8: 1[14$, c. $8,24,45]$. Подобная закономерность прослеживается и в могильниках эпохи бронзы на территориях Словакии [41, с. 88], Средней Германии [63], а также Поволжья [21]. М.Б. Медникова считает характерной чертой степных сообществ ранней бронзы двукратное или даже троекратное преобладание мужских погребений над женскими [19, с. 211]. При этом в более поздних группах белозерского населения отмечено преобладание женских индивидов и значительный процент детей [7, с. 99]. Такую же ситуацию упоминает и К. Кёль на других могильниках Европы [41, с. 233]. Очевидно, что спорадически исследованные группы не дают общей картины соотношений полов. В то же время такое соотношение является социально определяющей характеристикой каждого микросообщества. Подавляющее преобладание мужчин, как и полное отсутствие женщин, характерно для случайных выборок профессиональных групп (военных, кочевых, торговых) или для палеопопуляций, в которых существовала социальная, половая, возрастная дифференциация обряда погребения.

Интересным является факт обнаружения в Сугоклейском кургане среди представителей ямной культуры погребения ребенка 1-2 лет. Если дети второго возрастного периода могли сопровождать взрослых в дале- ких кочевьях или переходах с целью торговли, то наличие маленького ребенка предполагает участие в них женщин, поскольку дети такого возраста еще были привязаны к матери. Судя по возрасту появления гипоплазии эмали зубов в кочевнических сообществах, маркирующего в некоторых случаях время отлучения ребенка от груди, этот период мог длиться до трех лет и дольше.

В то же время наличие двух женских и детского погребения в группе культуры Бабино возможно является индикатором оседлости этой группы.

Основным маркером степени приспособленности к среде является средний возраст смерти группы населения. У взрослых представителей ямной культуры Сугоклеи он составил 45,7 лет (табл. 2). Этот показатель один из наиболее высоких среди всех до сих пор исследованных групп, за исключением серии Куюм, где средний возраст смерти в мужской выборке, по данным М.Б. Медниковой, составил 46,9 лет [19, с. 273].

Возраст смерти представителей ямной культуры Сугоклеи несколько превышает рамки, характерные в целом для населения ямной культурно-исторической общности Северного Причерноморья, и, вероятно, указывает на их высокий социальный статус. Возраст смерти людей бабинской культуры ниже этого показателя на 9 лет (несмотря на то что среди последних один индивид достиг возраста 60-70 лет) и в целом ниже, чем у представителей той же культуры на сопредельных территориях (табл. 2).

Прижсзненная длина тела (или рост) человека в значительной мере зависит от наследственности. На ее величину влияют диеты, условия жизни, физические нагрузки в детском и подростковом возрасте [69; 70]. Эпохальная динамика показателя предположительно находится под влиянием глобальных факторов среды, в первую очередь изменений климата [16].

Длина тела мужчин «ямников» составляет 169 [47], 172 [35] или 174,5 [60] см. Некоторая разница выявлена между ранними (скорченными на спине) и поздними (скорченными на боку) погребениями. Первые - выше на 4,5-7,6 см в зависимости от метода определения. У представителей культуры Бабино 


\section{БИОАРХЕОЛОГИЯ ДРЕВНИХ И СРЕДНЕВЕКОВЫХ ПОПУЛЯЦИЙ}

этот показатель у мужчин составил 172,8 [47], $172,1[35]$ и 173,4 [60] см. Из трех исследованных групп «ямники», погребенные на спине, оказались самыми высокими.

В целом показатели длины тела погребенных в Сугоклейском кургане не отличались от таких же во многих культурах эпохи бронзы. Например, на территории Германии, Польши и Австрии рост мужчин уньетицкой культуры составлял 167-180 см [64], а рост мужчин культуры Нитра на территории Словакии, по данным К. Кёль, в среднем составлял 171 см по формулам К. Пирсона и 167 см - по методике Э. Брайтингера [41, с. 228]. Для мужчин ямной культуры Нижнего Подонья рост определен в среднем как 170,8 см [2], «ямники» же Ставропольского края отличались более высоким ростом - около 173 см [18].

Интересно, что в сборных сериях представителей трех относительно последовательных культур эпохи бронзы (ямной, катакомбной и бабинской), сформированных С.И. Круц, рост мужчин постепенно уменьшается [14]. На этом фоне показатели, определенные для Сугоклейского кургана, вероятно, являются локальными вариантами. Повышенные показатели представителей культуры Бабино, очевидно, отражают определенную стадию приспособления одной группы населения к условиям окружающей среды.

В числе генетических аномалий были исследованы наличие метопического шва во взрослом возрасте, присутствие шовных и родничковых косточек, ранняя облитерация черепных швов, редукция лобного синуса, грудинное отверстие, шейное ребро, 6-сегментный крестец и несрастание дуг позвонков в области крестца (Spina bifida). У «ямников» эти признаки исключительно редки и встречаются лишь в единичных случаях (у четырех из 11 индивидов), что, возможно, указывает на случайность этой выборки. Наоборот, судя по относительной множественности встреченных признаков, таких как редукция лобных синусов или метопический шов, найденных каждый по два раза, представители «бабинской» группы могли состоять в родственных отношениях. Однако хаотичное накопление таких признаков может служить и неспецифическим маркером стрессового давления на популяцию [33; 71]. У подавляющего большинства (11 из 12 человек) в погребениях этой культуры мы наблюдали наличие одного или нескольких таких признаков. За исключением двух упомянутых, они не повторялись. Это наталкивает на мысль о значительном давлении стрессовых факторов на популяцию.

Учитывая особенности формирования выборок, определение стрессового давления на детскую часть популяции как наиболее чувствительную по показателям детской смертности невозможно. В связи с этим единственным источником такой информации остаются так называемые маркеры эпизодического стресса у детей и взрослых, формирующиеся в детском возрасте, а также следы заболеваний на костях детей, которые могли привести к их гибели.

Поперечная гипоплазия эмали зубов в погребениях Сугоклейского кургана «ямного» периода найдена лишь у детей и подростка (в $30 \%$ случаев). Отсутствие гипоплазии эмали у взрослых представителей ямной культуры, возможно, является показателем высокого уровня жизни этих людей. В то же время у взрослых представителей культуры Бабино из Сугоклейского кургана гипоплазия присутствует у половины индивидов (6 из 11). В исследованных ранее группах эпохи ранней и средней бронзы частота встречаемости этого признака колеблется в пределах 40-60 \% [7, с. 294]. Гипоплазия эмали присутствует у трети всех представителей «ямной» группы Сугоклейского кургана, что соответствует такому же показателю, обнаруженному М. Шульцем в «ямной» серии Баштечек [53, с. 30], а также Е. Перервой [21] у представителей ямной культуры территории Нижнего Поволжья (там гипоплазия обнаружена только у мужчин). У близкого территориально населения ямной культуры и культуры Бабино из округи г. Орджоникидзе (неопубликованные данные автора), а также у представителей населения эпохи бронзы Северного Кавказа [39] эти показатели также высоки (табл. 3). В детских популяциях эпохи бронзы на территории Европы частота гипоплазии колебалась в пределах 18,2-61,9\% [56; 57].

Задержки формирования эмали зубов, способствующие появлению гипоплазии, могут быть вызваны целым спектром причин. 
Среди них не последнее место занимают периоды эпизодического или длительного голода (алиментарный стресс). К причинам гипоплазии относятся болезни желудочно-кишечного тракта, а также инфекционные детские и паразитарные заболевания [38; 49]. Болезни, как и голод, приводят к повышенному потреблению организмом витаминов или микроэлементов. Подобные состояния при длительном течении вызывают дефицитные заболевания. Наиболее значимыми из них являются анемии и цинга.

Одним из симптомов анемии является Cribra orbitalia. Этот признак в исследованной группе ямной культуры обнаружен у детей и подростка. Как правило, анемия является следствием слабого поступления железа с пищей и/или нарушением его метаболизма [3]. Последнее может быть связано с алиментарным дефицитом витаминов группы В [67], паразитарными [17], инфекционными, онкологическими заболеваниями или отравлениями тяжелыми металлами [41, с. 269, 288$].$

Кроме изменений в орбитах или на своде черепа, признаком анемии является заполнение медуллярной полости новообразованной мелкой губчатой костной тканью ${ }^{2}$. Вероятной причиной образования этого симптома у «ямников» Сугоклеи, за исключением онкологии, признаки которой обнаружены у одного, а возможно и трех индивидов, могут быть паразитарные инфекции или же определенные недостатки питания во время длительного кочевья.

Пористость орбит не всегда является симптомом анемии. Некоторые исследователи считают этот признак неспецифическим маркером стресса $[4$, с. $109 ; 7$, с. 80]. «Анемическая» Cribra orbitalia морфологически отличается от пористости орбит, имеющих причиной другие дефицитные состояния, инфекции в области орбит и т. д. [56].

Последствия недостатка витамина $C$ найдены у трех детей из погребений «ямной» группы. Дети, вероятно, с трудом переносили тяготы длительных переходов. Наличие гипоплазии эмали у них свидетельствует о детских заболеваниях, которые ослабили иммунитет и привели к их гибели при попадании в сложные условия среды.

К сожалению, при отсутствии детских погребений зафиксировать наличие дефицит- ных состояний и детских болезней у представителей культуры Бабино не представляется возможным.

Состояние зубной системы и заболевания зубов. Изношенность жевательной поверхности $[43 ; 48 ; 58]$ во всех возрастных группах несколько более интенсивна у представителей ямной культуры Сугоклеи в сравнении с культурой Бабино. При этом отмечено образование вторичного дентина у представителей обеих культур. Процессы изнашивания зубов проходили относительно медленно.

Микротравмы эмали (chipping), определяющие физические нагрузки на зубы, найдены у «ямников» при большей средней стертости немного реже, чем у «бабинцев» (табл. 4). Микротравмы эмали и травмы зубов у последних расположены на молярах, клыках и резцах. Так же локализуется и гиперцементоз на корнях зубов у «бабинцев». В то же время у «ямников» основные механические нагрузки, судя по расположению гиперцементоза и микротравм, испытывали лишь моляры.

По данным С. Тур и соавторов, травмы эмали широко (около 80 \% индивидов) распространены у скотоводов афанасьевской культуры Алтая [29]. По аналогии с популяциями алеутов, эскимосов и североамериканских индейцев [61], наиболее вероятной причиной такой травматизации С. Тур и М. Рыкун считают случайное попадание на зубы мелких костей, застрявших в мясе [28].

На равномерность изношенности жевательной поверхности эмали зубного ряда по некоторым предположениям влияет тип диет. С одной стороны, у людей, питающихся растительной и зерновой пищей, основная нагрузка попадает на моляры, скорость стирания которых по отношению к передним зубам будет большей. С другой стороны, ускоренное стирание передних зубов может быть обусловлено употреблением в пищу копченого или жаренного на огне мяса [27, с. 255]. Мы рассмотрели коэффициент стертости клыков ко второму моляру, несколько отступив от приведенной Б. Смит методики [58]: коэффициент рассчитан по соотношению изношенности клыка ко второму моляру. Повышение коэффициента определяется повышением нагрузок на передние зубы либо же сниженной нагрузкой на моляры. 


\section{БИОАРХЕОЛОГИЯ ДРЕВНИХ И СРЕДНЕВЕКОВЫХ ПОПУЛЯЦИЙ}

Соотношение стертости клыков к стертости моляров варьирует в возрастных группах, однако стабильно понижается к 40-50 годам. Вероятно, такие изменения отражают возрастную дифференциацию нагрузок на зубы. В большинстве исследованных культурных групп эпохи бронзы (материал находится в стадии обработки) в подростковом и молодом возрасте более изношенными являются передние зубы. Предположительно, изменение соотношения стертости зубов с возрастом происходит вследствие постепенного перехода от мясной к растительной или к более мягкой пище, что хорошо прослеживается у «ямников» Сугоклеи (табл. 5).

Наиболее высокие значения индекса наряду с травмами эмали резцов наблюдались в Сугоклейском кургане у двух женщин из могил культуры Бабино. Возможно, они использовали зубы в качестве рабочего инструмента.

С мясной диетой, а также употреблением пищи, богатой волокнами, связано и появление так называемых интерпроксимальных борозд на зубах у исследуемых «ямников», погребенных на спине, и у 6 из 11 «бабинцев». Эти борозды среди прочего считаются последствиями удаления волокон пищи из межзубных промежутков с помощью ниток или зубочисток [62].

Высокая частота следов воспалительных процессов в деснах у представителей культуры Бабино Сугоклеи [10] может быть связана с употреблением в пищу вяленой или высушенной рыбы, аналогично популяциям Русского Севера [25]. Острые воспаления у обеих женщин и хронические рецидивирующие у мужчин могут отражать также и особенности личной гигиены. В то же время подобные изменения у представителей «ямников» (табл. 4), судя по сопутствующим процессам, могли быть следствием различных гормональных нарушений и инфекций.

Отсутствие кариеса в исследуемых группах соответствует показателям по другим группам представителей скотоводческих культур эпохи бронзы [7, с. $293 ; 17$, с. $275 ; 18$, c. 49; 26]. На территории Степного Поднепровья и Поволжья частота кариеса не превышает $5 \%$ [14; 21], у представителей ямной культуры и культуры Бабино в Сугоклейском кургане, а также носителей культуры Бабино в округе современного Орджоникидзе кариес отсутствует. Спорадически случаи этого заболевания найдены у представителей ямной культуры из лесостепных Баштечек, где кариес был обнаружен у двух индивидов (11\%) группы [53] и «ямников» Орджоникидзе, из которых точечные дефекты присутствовали у 4 человек (15\% индивидов, или $0,8 \%$ зубов) (неопубликованные исследования автора). По одному зубу, пораженному точечным кариесом, найдено у двух женщин из погребения культуры шаровидных амфор на Подолье $(28,6 \%$ индивидов, или 1,7 \% зубов) [9]. Ю. Грески и Н. Березина также отмечают редкость кариеса в погребениях эпохи бронзы Северного Кавказа [39]. Из сказанного можно предположить, что кариес в эпоху ранней и средней бронзы был явлением достаточно случайным, по крайней мере, на территориях Восточной Европы, Поволжья и Северного Кавказа. Одновременно большинство вышеупомянутых исследователей отмечает значительное поражение зубным камнем. Последний присутствует почти у всех «ямников» и «бабинцев» Сугоклеи, включая детей.

М.В. Добровольская настаивает, что такое соотношение зубного камня и кариеса, как и равномерное тотальное распространение зубного камня, может свидетельствовать об общности представителей культур эпохи бронзы [7, с. 292] и отражать преимущественно белковые диеты.

Воспалительные процессы в области кончиков корней зубов, к числу которых относятся гранулемы и реже - абсцессы, были найдены у большинства представителей культуры Бабино, а также у пяти «ямников». Причиной таких реакций могли быть воспаления тканей вокруг зуба или же травмы этих зубов. Распространение прижизненной утраты зубов, найденное у части «ямников» и трети «бабинцев», при низких показателях кариеса характерно для скотоводческих степных популяций и указывает на значительные механические нагрузки на зубную систему [19], что подтверждает также высокая стертость передних зубов, распространение микротравм эмали и гиперцементоза.

Инфекиионные болезни и воспаления. Среди общих черт, характерных для представителей ямной и бабинской культур, погребен- 
ных в Сугоклейском кургане, можно отметить очень высокий процент заболеваний верхних дыхательных путей и среднего уха. Однако причины их возникновения могут быть различными для представителей обеих исследованных групп.

Соотношение распространения зубных патологий и следов ринитов среди погребенных в кургане привело к выводу о том, что основной причиной синуситов у «ямников» были риногенные инфекции. Все взрослые и часть детей страдали воспалениями околоносовых пазух и мастоидитами, в то время как последствия отитов найдены у 71 \% взрослых индивидов. Среди «бабинцев» Сугоклеи 70 \% взрослых имели следы воспалений околоносовых пазух, в то время как 83 \% страдали воспалением среднего уха. В Днепровском Правобережье исследована всего одна группа населения (Баштечки), где подобные изменения вообще не обнаружены [54]. Половина взрослого населения Ельшовцев (Словакия) в период ранней бронзы имела признаки воспалений околоносовых пазух. К. Кёль связывает их с климатическими, профессиональными (обработка бронзы) и жилищными условиями [41, с. 244]. В этих группах количество заболеваний среднего уха также относительно низкое - около 30 \% [41, с. 246].

Распространение респираторных инфекций зависит от множества факторов, среди которых - географическая широта, высота над уровнем моря, климат, в частности, влажность воздуха [34; 54]; условия жизни [42; 54; 68], социальный статус популяции [54]; возраст и пол человека [46].

Можно предположить, что открытые степные пространства с постоянно дующим ветром и пребывание рядом с открытым огнем способствовали ослаблению слизистых оболочек и распространению воспалительных процессов области верхних дыхательных путей и среднего уха в обеих исследованных группах населения.

Важно отметить, что на непосредственный постоянный контакт поверхностных областей слизистых оболочек с раздражителем у представителей культуры Бабино, в отличие от «ямников», может указывать высокая частота следов ринитов и острых и хронических воспалений внешнего ушного прохода.
К таким относятся некроз стенки внешнего ушного прохода, многослойные отложения новообразованной кости на дне и стенках ушных проходов, симметричные экзостозы ушных проходов. Последние возникают вследствие гиперемии и воспаления при попадании в уши холодной (ниже $19^{\circ}$ ) воды [40] или в сочетании близости воды (независимо от температуры) и холодного ветра [45; 65]. Медицинские исследования показали, что любой вид деятельности, связанный с водными пространствами, даже не требующий погружения головы, повышает риск появления экзостоз ушных проходов [36; 50; 66]. В древних популяциях частота этого признака значительно превышается в зависимости от близости и использования водных ресурсов [32; 45]. Наиболее вероятной причиной высокой частоты (55 \%) этого признака у «бабинцев» Сугоклеи в сочетании с другими признаками, по моему мнению, может быть активное использование местного водного ресурса, например, ловля рыбы, добывание других речных животных или растений [10]. При этом нам неизвестно, была ли река, на берегу которой обитали эти люди, мелководной или глубоководной в период проживания там данной группы населения. Часть этих людей могла прийти на берега Ингула или Сугоклеи из более влажных мест обитания. Такое предположение может частично объяснить различия в погребальном обряде «бабинцев» кургана Сугоклея [15], в том числе и присутствие тут погребений в «лодках». Миграционную гипотезу появления экзостоз у катакомбников Нижнего Поволжья высказал Е.В. Перерва с соавтором [22].

Признаки менингеальных реакиий были обнаружены как у «ямников», так и у «бабинцев» Сугоклеи. Однако причины этих реакций, судя по сопутствующим изменениям, могли быть разными. В то время как у первых они связаны с гормональными и метаболическими нарушениями, а также, в одном случае, со злокачественной опухолью, у вторых основной причиной были осложнения хронических инфекций. В группах ранней бронзы на территории Словакии частота следов менингеальных реакций оказалась относительно низкой (12,8 \% и 16,8 \% у взрослых индивидов культур Нитра и Уньетицы соответственно) [41, с. 249]. 


\section{БИОАРХЕОЛОГИЯ ДРЕВНИХ И СРЕДНЕВЕКОВЫХ ПОПУЛЯЦИЙ}

С одной стороны, можно предположить, что в степях Украины заболеваемость различными инфекциями была намного выше, чем в Центральной Европе. С другой стороны, сопротивляемость болезням здесь могла быть достаточно высокой, что позволяло большему количеству людей, перенесших инфекции, доживать до зрелого и пожилого возраста. Для получения более определенных выводов необходимо продолжение исследований.

Близкое соседство с одомашненными и синантропными животными в древних популяциях привело к переносу заболеваний домашнего скота в человеческий организм. $T y$ беркулез является одним из таких заболеваний и негативным последствием одомашнивания. В неолите-бронзе это заболевание было достаточно распространено на всей территории Европы как в скотоводческих, так и оседлых земледельческих популяциях [51]. Латентная хроническая форма этого заболевания фиксируется на внутренней поверхности основания черепа в виде маленьких, слитых между собой гроздевидных вдавлений, так называемых Grübchen [55; 59]. Похожие изменения найдены у представителей ямной $(37,5 \%)$ и бабинской $(12,7 \%)$ культур. В большинстве случаев они сопровождаются другими признаками воспалительной реакции в области оболочек мозга, но всегда в латентной, хорошо зажившей форме. Таким образом, присутствие туберкулеза в обеих группах исключить нельзя.

Результаты. Исследованные представители ямной культуры, погребенные в кургане Сугоклея, представляют собой «случайно» сформированную группу, не являющуюся популяцией. Люди более древней части группы, погребенные на спине, в течение жизни испытывали малое давление стрессовых факторов. Это позволило им дожить до зрелости. Основная смертность попадала на возраст после 40 лет. Наиболее часто определены проникающие травмы головы, инфекции верхних дыхательных путей и среднего уха, онкологические заболевания, возможно, заболевания кровеносных сосудов. Наиболее частыми причинами детской смертности оказались последствия инфекций, анемия и недостаток витамина $\mathrm{C}$, вероятно, обусловленные ограничениями питания в процессе кочевания.
В более поздней группе погребенных на боку проявление и частота следов заболеваний, вероятно, свидетельствуют о более слабом иммунитете. У нескольких человек выявлены признаки лептоменингита.

В обеих группах значительные нагрузки на зубы после 30-40 лет, отсутствие кариеса и тотальное поражение зубным камнем указывают на употребление жесткой, нерафинированной, в основном белковой пищи.

Изменения скелета у группы носителей культуры Бабино указывают на относительно спокойный образ жизни. При этом давление факторов среды на популяцию, к которой относились исследованные индивиды, выражается в значительном количестве маркеров пренатального стресса. При этом количество индивидов с маркерами эпизодического стресса относительно мало. То есть либо стресс был слабым и действовал не на всю популяцию, либо же сильнодействующие негативные факторы снижали иммунитет и дети рано погибали. Судя по очень плохой сохранности единственного детского погребения, постпогребальные условия способствовали полному уничтожению детских останков. Относительно низкий показатель возраста смерти взрослых также отражает влияние негативных факторов среды. Лишь один человек дожил до старческого возраста, основное же количество мужчин и женщин погибло в возрасте между 25 и 40 годами.

В данной группе отсутствуют следы дефицитных заболеваний. Равномерная стертость зубов, наличие интерпроксимальных борозд почти у половины индивидов, отсутствие кариеса, всеобщее поражение зубным камнем свидетельствуют о волокнистой, богатой белком, преимущественно мясной пище. Кроме того, значительное количество микротравм и переломов эмали зубов, гиперцементоз и образование гранулем, обширные воспалительные процессы в пародонте (вследствие травмирования?) вызваны значительными нагрузками на зубную систему. Эти нагрузки, среди прочего, могут быть обусловлены употреблением сухой или вяленой рыбы, мяса, а также моллюсков и орехов.

Совокупность патологических признаков подтверждает выводы, полученные в результате исследования травм и костных марке- 
ров физических нагрузок. Они позволяют отнести эту группу к скотоводческим популяциям. Косвенным подтверждением таких выводов может быть обнаружение в нескольких погребениях костей домашних животных (быка, козы, овцы) [31].

У мужчин и женщин, наряду с высокой частотой заболеваний среднего уха, обнаружен высокий процент экзостоз ушного прохода. Такое явление позволяет предположить некоторую зависимость популяции от водных ресурсов. Группа, очевидно, занималась и другими сопутствующими видами хозяйствования. К сожалению, пока не найдены археологические или палеозоологические подтверждения рыболовства у племен культуры Бабино. При этом погребальный обряд связывает большинство индивидов, имеющих экзостозы во внешнем ушном походе, с лесостепными вариантами культуры Бабино.

Сравнительное изучение комплекса морфологических и патологических признаков двух малых выборок позволило описать некоторые условия жизни и хозяйствования групп ямной и бабинской культур, кочевавших в степях Северного Причерноморья. Нельзя отрицать, что колебания климата оказывали значительное влияние на формирование типа хо- зяйствования обеих групп, в том числе и на их мобильность. Хозяйственный уклад и социальный статус могут расцениваться как наиболее значимые факторы, влиявшие на состояние здоровья исследованных людей эпохи бронзы. При этом встречаемость некоторых заболеваний и комплекс изменений скелета подтверждает миграционную теорию происхождения синкретического погребального обряда культуры Бабино в этом регионе. Полученные выводы могут быть подтверждением воздействия смены биотопов как следствий миграций на частоту и проявления заболеваний у древнего населения.

\section{ПРИМЕЧАНИЯ}

${ }^{1}$ Автор выражает признательность авторам раскопок кургана Сугоклея, к.и.н. А.В Николовой и к.и.н. Ю.В. Болтрику, а также к.и.н. С.В. Полину за предоставленную возможность исследовать материалы из кургана Сугоклея и курганов в округе г. Орджоникидзе (Покров). Также автор благодарит коллег, проф. М. Шульца, к.и.н. И.Д. Потехину, к.и.н. Л.В. Литвинову, Ю.В. Ушкову, д.и.н. Р.А. Литвиненко за советы и помощь в интерпретации материала.

2 Данное утверждение высказано проф. Михаэлем Шульцем (M. Schultz) при личном общении с автором статьи. 


\section{БИОАРХЕОЛОГИЯ ДРЕВНИХ И СРЕДНЕВЕКОВЫХ ПОПУЛЯЦИЙ}

\section{ПРИЛОЖЕНИЕ}

Таблица 1. Половозрастной состав погребений Сугоклейского кургана (количество индивидов)

Table 1. Sex and age distribution of the burials on Sugoklea barrow (number of individuals)

\begin{tabular}{|l|c|c|c|c|}
\hline $\begin{array}{c}\text { Культурная принад- } \\
\text { лежность / поло- } \\
\text { возрастные группы }\end{array}$ & Мужчины & Женщины & $\begin{array}{c}\text { Дети } \\
\text { до 14 лет }\end{array}$ & Всего \\
\hline Ямная культура & 8 & 0 & 3 & 11 \\
\hline Культура Бабино & 11 & 2 & 1 & 14 \\
\hline
\end{tabular}

Таблицяа 2. Средний возраст смерти в популяциях бронзового века Поднепровья и Подонья

Table 2. Average age of death in the Bronze Age populations of the Dnieper and Don regions

\begin{tabular}{|l|c|c|c|c|}
\hline \multicolumn{1}{|c|}{ Серия } & Мужчины & Женщины & $\begin{array}{c}\text { Показатель } \\
\text { без учета детской } \\
\text { смертности }\end{array}$ & $\begin{array}{c}\text { Показатель } \\
\text { с учетом детской } \\
\text { смертности }\end{array}$ \\
\hline ЯК Сугоклея & 45,7 & - & 45,7 & 32,5 \\
\hline ЯК Поднепровья [14] & 41,0 & 33,0 & 31,0 & - \\
\hline ЯК Подонья [21] & 39,4 & - & 39,2 & 32,7 \\
\hline КК Поднепровья [14] & 39,9 & 35,4 & - & 27,0 \\
\hline КБ Сугоклея & 36,7 & 32,5 & 36,7 & 34,8 \\
\hline КБ Поднепровья [14] & 41,0 & 44,0 & - & 38,7 \\
\hline «Срубники» Поднепровья [14] & 41,3 & 33,1 & - & 35,0 \\
\hline
\end{tabular}

Примечание. ЯК - ямная культура, КК - катакомбная культура, КБ - культура Бабино.

Note. ЯК - Yamnaja culture, КК - Catacomb culture, КБ - Babino culture.

Таблица 3. Частота встречаемости гипоплазии эмали у представителей культур эпохи бронзы

Table 3. Frequency of the transversal teeth enamel hypoplasia in the Bronze Age populations

\begin{tabular}{|l|c|c|c|c|c|c|c|}
\hline $\begin{array}{c}\text { Серия / } \\
\text { показа- } \\
\text { тель }\end{array}$ & $\begin{array}{c}\text { Сугоклея, } \\
\text { ямная ку- } \\
\text { льтура }\end{array}$ & $\begin{array}{c}\text { Сугоклея, } \\
\text { культура } \\
\text { Бабино }\end{array}$ & $\begin{array}{c}\text { Объединен- } \\
\text { ная серия } \\
\text { (ОАЕ), ямная } \\
\text { культура }\end{array}$ & $\begin{array}{c}\text { Объединен- } \\
\text { ная серия } \\
\text { (ОАЕ), куль- } \\
\text { тура Бабино }\end{array}$ & $\begin{array}{c}\text { Объединен- } \\
\text { ная серия } \\
\text { (ОАЕ), ката- } \\
\text { комбная ку- } \\
\text { льтура }\end{array}$ & $\begin{array}{c}\text { Северный Кавказ, } \\
\text { объединенная се- } \\
\text { рия представителей } \\
\text { разных культур } \\
\text { эпохи энеолита- } \\
\text { бронзы [39] }\end{array}$ & $\begin{array}{c}\text { Нижнее По- } \\
\text { волжье, ям- } \\
\text { наяьтура } \\
{[21]}\end{array}$ \\
\hline$\%$ & 30 & 54,5 & 69,2 & 57 & 95 & 63 & 30 \\
\hline $\mathrm{n}$ & 10 & 11 & 13 & 7 & 40 & 41 & - \\
\hline
\end{tabular}

Примечание. ОАЕ - курганы возле г. Орджоникидзе, Днепропетровская обл.; неопубликованные исследования автора.

Note. OAE - barrows near Ordjonikidze, Dnepropetrovsk region; unpublished results of the author. 
Таблица 4. Зубные заболевания у мужчин ямной культуры и культуры Бабино кургана Сугоклея

Table 4. Diseases of the teeth and jaws in the male population of the Yamnaja and Babino cultures from Sugoklea barrow

\begin{tabular}{|l|c|c|c|c|c|c|c|c|}
\hline \multirow{2}{*}{$\begin{array}{c}\text { Культурная принадлежность / } \\
\text { показатель }\end{array}$} & \multicolumn{4}{|c|}{ Ямники } & \multicolumn{4}{c|}{ Бабинцы } \\
\cline { 2 - 10 } & $\%$ 3/a & $N$ 3/a & $\% i$ & $N i$ & $\%$ 3/a & $N$ 3/a & $\% i$ & $N i$ \\
\hline Кариес & 0 & 131 & 0 & 7 & 0 & 251 & 0 & 11 \\
\hline Зубной камень & 53,4 & 131 & 100 & 7 & 80,9 & 251 & 100 & 11 \\
\hline Гранулемы / абсцессы & 15,9 & 138 & 71,4 & 7 & 8,9 & 213 & 60 & 10 \\
\hline Прижизненная утрата зубов & 39,9 & 138 & 42,9 & 7 & 0,9 & 213 & 20 & 10 \\
\hline Травмы эмали & 3,05 & 131 & 50 & 6 & 5,97 & 251 & 63,6 & 11 \\
\hline Межзубные борозды & 14,5 & 131 & 50 & 6 & 5,6 & 251 & 54,5 & 11 \\
\hline
\end{tabular}

Примечание. \% - процент больных; $N$ - общее количество; з/а - зубы / альвеолы; $i$ - индивиды. Note. $\%$ - percentage of the diseased; $N$ - total number; $3 / \mathbf{a}$ - teeth / alveoli; $i$-individuals.

Таблица 5. Соотношение стертости клыков и вторых моляров в возрастных группах населения эпохи бронзы в районе Сугоклеи и Орджоникидзе

Table 5. Teeth abrasion ratio (C/M2) in the age groups of the Bronze Age populations (Sugoklea and Ordjonikidze)

\begin{tabular}{|l|c|c|c|c|c|c|c|}
\hline \multicolumn{1}{|c|}{ Возрастная группа } & $n$ & $14-19,9$ & $20-29,9$ & $30-39,9$ & $40-49,9$ & $50+$ & Общее \\
\hline ЯК Сугоклеи, группа 1 (мужчины) & 5 & 3,0 & 1,50 & 1,29 & 0,85 & - & 1,12 \\
\hline ЯК Орджоникидзе (мужчины) & 8 & 3,5 & 1,95 & 1,45 & 1,16 & - & 1,99 \\
\hline ЯК Орджоникидзе (женщины) & 2 & - & 1,85 & 1,5 & - & - & 1,68 \\
\hline КК Орджоникидзе (мужчины) & 18 & 2,69 & 2,22 & 2,08 & 1,16 & - & 2,09 \\
\hline КК Орджоникидзе (женщины) & 6 & 2,25 & 1,98 & 1,07 & - & 1,2 & 1,79 \\
\hline КБ Сугоклея (мужчины) & 8 & - & 1,75 & 2,13 & 1 & 1,26 & 1,61 \\
\hline КБ Сугоклея (женщины) & 2 & - & 2,86 & 2,49 & - & - & 2,67 \\
\hline КБ Орджоникидзе (мужчины) & 4 & - & 1,22 & 2,1 & 3 & - & 1,92 \\
\hline
\end{tabular}




\section{СПИСОК ЛИТЕРАТУРЫ}

1. Алексеев, В. П. Остеометрия. Методика антропологических исследований / В. П. Алексеев. М. : Наука, 1966. - 251 с.

2. Боруцкая, С. Б. Остеологическое и палеопатологическое исследование населения ямной культуры эпохи бронзы Ростовской области / С. Б. Боруцкая, А. О. Афанасьева // Вестник антропологии. 2009. - № 17. - С. 108-116.

3. Бужилова, А. П. Анемия у древнего населения как один из индикаторов среды / А. П. Бужилова // Вестник антропологии. -2001.-Вып. 7.-С. 227-236.

4. Бужилова, А. П. Историческая экология человека. Методика биологических исследований / А. П. Бужилова, М. В. Козловская, М. Б. Медникова. - М. : Старый Сад , 1998. - 260 с.

5. Герасимов, М. М. Восстановление лица по черепу (современный и ископаемый человек) / М. М. Герасимов. - М. : Изд-во АН СССР, 1955. 303 с. - (Труды Ин-та этнографии АН СССР (новая cep.); т. XXVIII).

6. Дерумс, В. Я. Болезни и врачевание в древней Прибалтике / В. Я. Дерумс. - Рига : Зинатне, 1970. - 197 c.

7. Добровольская, М. В. Население эпохи бронзы в Прикубанье: некоторые аспекты изучения антропологического источника / М. В. Добровольская // ОПУС: Междисциплинарные исследования в археологии. -2005. - Вып. 4.-С. 95-112.

8. Козак, О. Д. До питання про професійні остеологічні комплекси епохи бронзи. Методичні основи визначення комплексу візничого / О. Д. Козак //Археологічні дослідження Львівського університету. - 2014. - № 18. - С. 11-33.

9. Козак, О. Д. До питання про фізичні навантаження та захворювання населення культури кулястих амфор Хмельниччини (на матеріалі групового поховання з с. Іллятка) / О. Д. Козак // Старожитності культури кулястих амфор на Поділлі / під ред. В. Захарьєва. - Хмельницький : Цюпак А. А. - 2015. C. $61-112$.

10. Козак, О. Маркери окупаційного стресу серед носіїв культури Бабино. Освоєння водного простору / О. Д. Козак // ЕМІНАК. Scientific Quarterly Journal. - 2016. - № 4 (16). - C. 270-278.

11. Козак, А. Д. Погребения воинов эпохи бронзы с ударным оружием / А. Д. Козак // Stratum Plus. 2019. - № 2. - С. 251-266.

12. Козак, О. Д. Патологічні ознаки на скелеті як маркери міграцій / О. Д. Козак // Археологія. 2019. - № 1. - С. 14-27.

13. Козак, О. Д. Захворювання людей ямної культури за матеріалами поховань Сугоклейського кургану / О. Д.Козак // Історична антропологія та біоархеологія України. - № 2-3. - (В печати).
14. Круц, С. И. Палеоантропологические исследования Степного Приднепровья: (Эпоха бронзы) / С. И. Круц. - Киев : Наук. думка, 1984. - 207 с.

15. Литвиненко, Р. О. Культурне коло Бабине (за матеріалами поховальних пам'яток) : дис. ... д-ра іст. наук : 07.00.06 / Роман Олександрович Литвиненко. - Київ, 2009. - Ф. 12. - Оп. 2. - Спр. 87. - 387 с.

16. Медникова, М. Б. Эпохальная изменчивость размеров тела человека: мифы и реальность / М. Б. Медникова // ОПУС: Междисциплинарные исследования в археологии. - 2002. - Вып. 1-2. С. $59-65$.

17. Медникова, М. Б. Палеоэкология Центральной Азии по данным антропологии / М. Б. Медникова // Антропоэкология Центральной Азии. - М. : Науч. мир, 2005. - С. 256-289.

18. Медникова, М. Б. Данные антропологии к вопросу о социальных особенностях и образе жизни населения восточного бассейна р. Маныч в эпоху бронзы (по материалам из раскопок могильника Чограй IX) / М. Б. Медникова // Вестник антропологии. -2006. - Вып. 14. - С. 41-51.

19. Медникова, М. Б. Курота-2 и Куюм: данные антропологии к реконструкции условий жизни алтайских афанасьевцев / М. Б. Медникова // Афанасьевский сборник / под ред. Н. Ф. Степановой, А. В. Полякова. - Барнаул : Азбука, 2010. C. 200-224.

20. Ніколова, А. В. Поховання культури Бабине Сугоклейської могили / А. В. Ніколова, С. М. Разумов // Археологія. - 2012. - № 3. - С. 96-108.

21. Перерва, Е. В. Палеопатологические особенности населения Нижнего Поволжья из подкурганных захоронений эпохи ранней бронзы / Е. В. Перерва // Известия Волгоградского государственного педагогического университета. - 2013. - № 8 (83). C. 47-53.

22. Перерва, Е. В. Маркер стресса или миграций (к вопросу об интерпретации экзостоза слухового прохода на костных материалах населения эпохи средней бронзы из могильников Нижнего Поволжья) / Е. В. Перерва, А. Н. Дьяченко // Вестник археологии, антропологии и этнографии. - 2017. Вып. 4 (39). - С. 61-78.

23. Потєхіна, І. Д. Звідки прийшли люди з візками: антропологія й археогенетика ямних поховань Сугоклейського кургану / І. Д. Потєхіна // Ольвійський форум (пам'яті В. В. Крапівіної) до 150-річчя дослідження Ольвії : матеріали ІІ міжнар. конф. (м. Миколаїв, 4-6 травня 2018 р.). - Миколаїв : Лукомор'є, 2018. - С. 32-34.

24. Потєхіна, I. Д. Носії ямної культури Сугоклейського кургану за даними краніології і археогенетики в антропологічному контексті Північнопонтійського регіону/ І. Д. Потєхіна // Історична антропологія та біоархеологія України. - Вип. 3. - (В печати). 
25. Ражев, Д. И. Стоматологическое здоровье средневекового населения лесной зоны Западной Сибири / Д. И. Ражев, М. П. Рыкун, Е. О. Святова // Вестник археологии, антропологии и этнографии. - 2011. - Вып. 1 (14). - С. 103-115.

26. Святко, С. В. Диета населения афанасьевской культуры по данным изотопного анализа, анализа зубных патологий и статистического анализа погребений / С. В. Святко // Афанасьевский сборник / под ред. Н. Ф. Степановой, А. В. Полякова. Барнаул : Азбука, 2010. - С. 225-232.

27. Тур, С. С. Зубные маркеры палеодиеты в краниологической серии населения афанасьевской культуры Алтая / С. С. Тур // Афанасьевский сборник / под ред. Н. Ф. Степановой, А. В. Полякова. Барнаул : Азбука, 2010. - С. 251-258.

28. Тур, С. С. Краниологические материалы афанасьевской культуры Горного Алтая в палеоэкологическом аспекте исследования / С. С. Тур, М. П. Рыкун // Вестник антропологии. Научный альманах. -2006. - Вып. 14. - С. 102-108.

29. Тур, С. С. Население андроновской культуры Алтая по данным биоархеологического исследования / С. С. Тур, М. П. Рыкун // Известия алтайского государственного университета. - 2008. - № 42. - C. 191-198.

30. Ушкова, Ю. Травми та трепанації на черепах 3 поховань ямної культурно-історичної спільності / Ю. Ушкова, О. Козак // Магістеріум. 2011. - № 45 (Археологічні студіï) . - С. 29-34.

31. Яніш, Є. Остеологічні матеріали з поховань ямної і бабинської культур Сугоклейської могили / Є. Яніш // Історична антропологія та біоархеологія України.- № 2-3. - (В печати).

32. Auricular Exostoses in the Prehistoric Population of Gran Canaria / J. Velasco-Vazquez [et al.] // American Journal of Physical Anthropology. 2000. - Vol. 112 (1). - P. 49-55.

33. Barnes, E. J. Developmental Defects of the Axial Skeleton in Paleopathology / E. J. Barnes. Niwot : University Press of Colorado, 1994. - 360 p.

34. Boocock, P. Maxillary Sinusitis in Medieval Chichester, England / P. Boocock, Ch. Roberts, K. Manchester // American Journal of Physical Anthropology. - 1995. - Vol. 98. - P. 483-495.

35. Breitinger, E. Zur Berechnung der Körperhöhe aus den langen Gliedmaßenknochen / E. Breitinger // Anthropologischer Anzeiger. 1938. - Bd. 14. - S. 249-274.

36. Fabiani, M. External Ear Canal Exostosis and Aquatic Sports / M. Fabiani, M. Barbara, R. Filipo // Journal for Otorhinolaryngology and its Related Specialties. - 1984. - № 46 (3). - P. 159164. - DOI: https://doi.org/10.1159/000275702.

37. Fuchs, K. Malnutrition in the Bronze Age: Scurvy in Population of Northern Caucasus / K. Fuchs,
N. Berezina, J. Gresky // Население юга России с древнейших времен до наших дней : материалы междунар. науч. конф. - Ростов н/Д : Изд-во ЮНЦ РАН, 2013. - C. 54-56.

38. Giro, C. M. Enamel Hypoplasia in Human Teeth: an Examination of its Causes / C. M. Giro //Journal of the American Dental Association. - 1947. - № 34 (5). P. 310-317.

39. Gresky, J. Oral Hygiene and Patterns of Dental Wear in Skeletons from Six Chalkolithic and Bronze Age Cemeteries in Northern Caucasus / J. Gresky, N. Berezina // Население юга России с древнейших времен до наших дней : материалы междунар. науч. конф. - Ростов н/Д : Изд-во ЮНЦРАН, 2013. - С. 33.

40. Kennedy, G. E. The Relationship Between Exostoses and Cold Water: a Latitudinal Analysis / G. E. Kennedy // American Journal of Physical Anthropology. - 1986. - Vol. 71 (4). - P. 401-415. DOI: https://doi.org/10.1002/ajpa.1330710403.

41. Koel, K. Paläopathologische und bioarchäologische Untersuchungen an den frühbronzezeitlichen Skeletfunden der Erwachsenenpopulation von Jelšovce (Slowakische Republik). Ein Beitrag zur Rekonstruktion des Gesundheitsstatus frühbronzezeitlicher Populationen / K. Koel. - Diss. Naturwiss. : Universität Hildesheim Hildesheim, 2011. - 386 S.

42. Merrett, D. Maxillary Sinusitis as an Indicator of Respiratory Health in Past Population / D. Merrett, S. Pfeiffer // American Journal of Physical Anthropology. - 2000. - Vol. 111. - P. 310-318.

43. Molnar, S. Human Tooth Wear, Tooth Function and Cultural Variability / S. Molnar // American Journal of Physical Anthropology. 1971. - vol. 34 (2). - P. 175-189. - DOI: https://doi.org/ 10.1002/ajpa.1330340204.

44. Nikolova, A.V. Die absolute Chronologie der Jamnaja-Kultur im nördlichen Schwarzmeergebiet aufder Grundlage erster dendrologischer Daten / A. V. Nikolova, E. Keiser // Eurasia Antiqua. - 2009. - Bd. 15. S. 209-240.

45. Okumura, M. M. M. Auditory Exostoses as an Aquatic Activity Marker: a Comparison of Coastal and Inland Skeletal Remains from Tropical and Subtropical Regions of Brazil / M. M. M. Okumura, C. H. C. Boyadjian, S. Eggers // American Journal of Physical Anthropology. - 2007. - Vol. 132. - P. 558567. - DOI: https://doi.org/10.1002/ajpa.20544.

46. Panhuysen, R. G. A. M. Chronic Maxillary Sinusitis in Medieval Maastricht, the Netherlands / R. G. A. M. Panhuysen, V. Coenen, T. Bruintjes // International Journal of Osteoarchaeology. - 1997. Vol. 7. - P. 610-614

47. Pearson, K. Mathematical Contributions to the Theory of Evolution. On the Reconstruction of the Stature of Prehistoric Races / K. Pearson // Philosophical 
Transactions of the Royal Society London. - 1899. № 192. - P. 169-244.

48. Perizonius, W. R. K. Diachronic Dental Research on Human Skeletal Remains Excavated in the Netherlands / W. R. K. Perizonius, T. J. Pot // Dorestad Cemetery on "The Heul". Berichten van de Rijksdienst voor het Oudheidkundig Bodemonderzoek. - 1981. Bd. 31. $-45 \mathrm{~S}$.

49. Piontek, J. Stress w populacjach pradziejowych: zalozenia, metody i wstepne wyniki badan / J. Piontek // Biologia populacji ludzkich wspolczesnych i pradziejowych / ed. by F. Rożnowski. - Siupsk : WSP, 1992. - S. 321-345.

50. Prevalence of Exostoses Surfers of the Basque Coast / X. Altuna Mariezkurrena [et al.] // Acta Otorrinolaringol Espaniol. - 2004. - Vol. 55. - P. 364-368. DOI:https:/doi.org/10.1016/S0001-6519(04)78537-4.

51. Roberts, Ch. A. The Bioarchaeology of Tuberculosis: A Global View on a Reemerging Diseases / Ch. A. Roberts, J. Buikstra.-Florida : University Press, 2003. $-368 \mathrm{p}$.

52. Schultz, M. Paläopathologische Diagnostik / M. Schultz // Anthropologie: Handbuch der vergleichenden Biologie des Menschen. Bd. 1 (1). Wesen und Methoden der Anthropologie / hrsg. von R. Knussmann. - Stuttgart : Fischer Verlag, 1988. S. $480-496$.

53. Schultz, M. Archäologische Skelettfunde als Spiegel der Lebensbedingungen früher Viehzüchter und Nomaden in der Ukraine/ M. Schultz // Золото степу. Археологія України / під ред. П. П. Толочко, В. Ю. Мурзіна. -Київ / Шлезвіг : [s. n.], 1991.-С. 27-42.

54. Schultz, M. Spuren unspezifischer Entzündungen an prähistorischen und historischen Schädeln / M. Schultz // Anthropologische Beiträge 4A, $84 \mathrm{pp}$ und 4B, Anthropologisches Forschungsinstitut Aesch und Anthropologische Gesellschaft in Basel, AeschBL / hrsg. von B. Kaufmann. - [S. 1. ] : [s. n.], 1993. $-84 \mathrm{~S}$.

55. Schultz, M. The Role of Tuberculosis in Infancy and Childhood in Prehistoric and Historic Population / M. Schultz // Tuberculosis. Past and present / ed. by G. Pálfi [et al.]. - Budapest : GBTB Foundation, 1999. - P. 503-507. -605 p.

56. Schultz, M. Paleohistopathology of Bone:ANew Approach to the Study of Ancient Diseases / M. Schultz //Yearbook of Physical Anthropology. - 2001. - Vol. 44.P. 106-147.

57. Schultz, M. The Role of Deficiency Diseases in Infancy and Childhood of Bronze Age Population / M. Schultz, T. H. Schmidt-Schultz // Palaeonutrition and Food Practices in the Ancient Near East - Venezia / ed. by L. Milano, F. Bertoldi, A. Canei. - [S. 1.] : [s. n.], 2008. - P. 1-18.

58. Smith, B. H. Patterns of Molar Wear in HunterGatherers and Agriculturalists / B. H. Smith // American
Journal of Physical Anthropology. - 1984. - Vol. 63.P. 39-56.

59. Tracking Down the White Plague: the Skeletal Evidence of Tuberculous Meningitis in the Robert J. Terry Anatomical Skeletal Collection / O. Spekker [et al.] // PLOS ONE. - 2020. - DOI: https://doi.org/10.1371/ journal.pone.0230418.

60. Trotter, M. Estimation of Stature from Intact Long Limb Bones / M. Trotter // Personal Identification in Mass Disasters / ed. by T. D. Stewart. - Washington : Smithsonian Press, 1970. - P. 85-97.

61. Turner II, C. G. Dental Chipping in Aleuts, Eskimos and Indians / C. G. Turner II, J. D. Cadien // American Journal of Physical Anthropology. 1969. - Vol. 31. - P. 303-210.

62. Ubelaker, D. H. Artificial Interproximal Grooving of the Teeth in American Indians / D. H. Ubelaker, T. W. Phenice, W. M. Bass // American Journal of Physical Anthropology.-1969.-Vol. 30 (1).-P. 145-149.

63. Ullrich, H. Neue Ergebnisse zur Frage nach der Verwandtschaftlichen Beziehungen der mitteldeutschen, böhmischen und mährischen Aunjetitze / H. Ullrich // Anthropos (Akta Anthropologického kongresu, Mikulov, 1961).-1963.-Bd. 1-5.-S. 271-274.

64. Ullrich, H. Das Aunjetitzer Gräberfeld von Grossbrembach, Teil 1: Anthropologische Untersuchungen zur Frage nach Entstehung und Verwandtschaft der thüringischen, böhmischen und mährischen Aunjetitzer / H. Ullrich. - Weimar : Beier \& Beran, 1972.-170 S.

65. Villotte, S. External Auditory Exostoses and Aquatic Activities During the Mesolithic and the Neolithic in Europe: Results from a Large Prehistoric Sample / S. Villotte, S. Stefanović, Ch. J. Knüsel // Anthropologie. - 2014. - Vol. LII/1. - P. 73-89.

66. Villotte, S. External Auditory exostoses and prehistoric aquatic resource procurement / S. Villotte, Ch. J. Knüsel // Journal of Archaeological Science. 2016. - Vol. 6. - P. 633-636. - DOI: https://doi.org/10. 1016/j.jasrep.2015.05.013.

67. The Causes of Porotic Hyperostosis and Cribra Orbitalia: a Reappraisal of the IronDeficiency-Anemia Hypothesis / P. L. Walker [et al.] //American Journal of Physical Anthropology. 2009. - Vol. 139 (2). - P. 109-125.

68. Wells, C. Bones, Bodies, and Disease; Evidence of Disease and Abnormality in Early Man / C. Wells. - N. Y. : Frederick A. Praeger, 1964. $288 \mathrm{p}$.

69. Wurm, H. Über die Schwankungen der durchschnittlichen Körperhöhe im Verlauf der deutschen Geschichte und die Einflüsse des Eiweißanteiles der Kost / H. Wurm // Homo. - 1982. Bd. 33. - S. 21-42.

70. Wurm, H. Konstituzion und Ernährung II: Zum Einfluß von Ernährung, insbesondere zum 
Einfluß von Nahrungseiweiß unterschiedlicher Quantität und Qualität auf die Konstitution nach Ernährungsversuchen - ein Vorbericht / H. Wurm // Homo. - 1987. - Bd. 38. - S. 34-58.

71. Živanovič, S. Ancient Diseases. The Elements of Palaeopathology / S. Živanovič ; trans. by L. F. Edwards). - L. : Methuen, 1982. - 285 p.

\section{REFERENCES}

1. Alekseev V.P. Osteometriya. Metodika antropologicheskikh issledovaniy [Osteometry Methodology of Anthropological Research]. Moscow, Nauka Publ., 1966. 251 p.

2. Borutzkaya S.B., Afanasyeva A.O., Osteologicheskoe i paleopatologicheskoe issledovanie naseleniya yamnoy kultury epokhi bronzy Rostovskoy oblasti [Osteological and Palaeopathological Study of the Population of Jamnaja Culture of the Bronse Age of Rostov District]. Vestnik antropologii [Bulletin of Anthropology], 2009, no. 17, pp. 108-116.

3. Buzhilova A.P. Anemiya u drevnego naseleniya kak odin iz indikatorov sredy [Anemia in the Ancient Population as One of the Indicators of the Environment]. Vestnik antropologii [Bulletin of Anthropology], 2001, no.7, pp. 227-236.

4. Buzhilova A.P., Kozlovskaya M.V., Mednikova M.B. Istoricheskaya ekologiya cheloveka. Metodika biologicheskikh issledovaniy [Historical Ecology of Human. Methodology of Biological Research]. Moscow, Staryy Sad Publ., 1998. $260 \mathrm{p}$.

5. Gerasimov M.M. Vosstanovlenie litsa po cherepu (sovremennyy i iskopaemyy chelovek) [Restoration of the Face on the Skull (Modern and Fossil Humans)]. Moscow, Izd-vo AN SSSR, 1955. 303 p. (Trudy Instituta etnografii AN SSSR (novaya seriya) [Proceedings of the Institute of Ethnography of the Academy of Sciences of the USSR (New Series)], vol. XXVIII).

6. Derums V.Ya. Bolezni i vrachevanie v drevney Pribaltike [Diseases and Healing in the Antient Baltic States]. Riga, Zinatne Publ., 1970. 197 p.

7. Dobrovolskaya M.V. Naselenie epokhi bronzy v Prikubanye: nekotorye aspekty izucheniya antropologicheskogo istochnika [The Bronze Age Population in Cuban Region: Some Aaspects of the Study of the Anthropological Sourses]. OPUS: Mezhdistsiplinarnye issledovaniya $v$ arkheologii [OPUS: Interdisciplinnary Study in Archaeology], 2005, iss. 4, pp. 95-112.

8. Kozak O.D. Do pytannia pro profesiini osteolohichni kompleksy epokhy bronzy. Metodychni osnovy vyznachennia kompleksu viznychoho [On the Professional Osteological Complexes of Bronze Age.
Metodological Approaches to the Bioarchaeological Diagnostic of the Cart Driver]. Arkheolohichni doslidzhennia Lvivskoho universytetu [Lviv University Archaeology Studies], 2014, iss. 18, p. 11-33.

9. Kozak O.D. Do pitannya pro fizichni navantazhennya ta zakhvoryuvannya naselennya kulturi kulyastikh amfor Khmelnichchini na materiali grupovogo pokhovannya z s. Illyatka [On the Physical Activity and Diseases of the Population of Globular Amphora Culture in Khmelnytskyi Region on the Material of Collective Burial from Ilyatka Village]. Zakharyev V., ed. Starozhitnosti kulturi kulyastikh amfor na Podilli [Antiquities of Globular Amphora culture in Podillya]. Khmelnitskiy, Tsyupak A.A., 2015, pp. 61-112.

10. Kozak O.D. Markery okupatsijnogo stresu sered nosiiv kultury Babino. Osvojennja vodnogo prostoru [Occupational Stress Markers in One Population of Babino Cultural Circle.Exploration of Water Resource]. EMINAK.Scientific Quarterly Journal, 2016, iss. 4 (16), pp. 270-278.

11. Kozak A.D. Pogreberniya voinov epokhi bronzy s udarnym oruzhiem [Bronze Age Burials with Blunt Weapons from the Sugokleja Barrow: Anthropological and Paleopathological Perspective]. Stratum Plus, 2019, no. 2, pp. 251-266.

12. Kozak O.D. Patolohichni oznaky na skeleti yak markery mihratsii [Pathological Signs on the Skeleton as Markers of Migrations]. Archeologia [Archaeology], 2019, no. 1, pp. 14-27.

13. Kozak O.D. Zakhvoriuvannia liudei yamnoi kultury za materialamy pokhovan Suhokleiskoho kurhan [Diseases of the Population of Yamna Culture. Sugoklea Barrow]. Istorychna antropolohiia ta bioarkheolohiia Ukrainy [Historical Anthropology and Bioarchaeology of Ukraine], no. 2-3. (to appear).

14. Kruts S.I. Paleoantropologicheskie issledovaniya Stepnogo Pridneprovia: (Epokha bronzy) [Paleoanthropological Studies of the Dnieper Region Steppe: (Bronze Age)]. Kiev, Naukova Dumka Publ., 1984. 207 p.

15. Litvinenko R.O. Kulturne kolo Babyne (za materialamy pohovalnyh pamjatok [The Circle Babine-Cultures After the Funeral Sites Archaeology]. Kyiv, 2009, f. 12, op. 2, spr. 87.387 p.

16. Mednikova M.B. Epokhalnaya izmenchivost razmerov tela cheloveka: Mify i realnost [The Stage Variability of Humen Body Parameters: Myths and Reality]. OPUS: Mezhdistsiplinarnye issledovaniya $v$ arkheologii [OPUS: Interdisciplinnary Study in Archaeology], 2002, iss. 1-2, pp. 59-65.

17. Mednikova M.B. Paleoekologiya Tsentralnoy Azii po dannym antropologii [Paleoecology of Central Asia After the Anthropological Data]. Antropoekologiya Tsentralnoy Azii [Anthropoecology of Central Asia], Moscow, Nauchnyy mir Publ., 2005, pp. 256-289. 
18. Mednikova M.B. Dannye antropologii k voprosu o sotsialnykh osobennostyakh i obraze zhizni naseleniya vostochnogo basseyna $r$. Manych v epokhu bronzy (po materialam iz raskopok mogilnika Chogray IX) [Anthropological Data on the Social Characteristics and Lifestyle of the Bronze Age Population of the Eastern Basin of the River Manychv (Based on Materials from Excavation of the Burial Ground Chograi IX)]. Vestnik antropologii [Bulletin of Anthropology], 2006, no. 14, pp. 41-51.

19. Mednikova M.B. Kurota-2 i Kuyum: dannye antropologii k rekonstruktsii usloviy zhizni altayskikh afanasyevtsev [Kurota-2 and Kuyum: Anthropological Data on the Reconstruction of Living Conditions of Altai Afanasyevites]. Stepanova N.F., Polyakov A.B., eds. Afanasyevskiy sbornik [Afanasiev Collection], Barnaul, Azbuka Publ., 2010, pp. 200-224.

20. Nikolova A.V., Razumov S.M. Pokhovannia kultury Babyne Suhokleiskoi mohyly [The Burials of Babino Culture in the Sugokleya Barrow]. Arkheolohiia [Archaeology], 2012, no. 3, pp. 96-108.

21. Pererva E.V. Paleopatologicheskie osobennosti naseleniya Nizhnego Povolzhya iz podkurgannykh zakhoroneniy epokhi ranney bronzy [Paleopathological Features of Lower Volga Region Population Dating Early Bronze Age from Burial Ground Tombs]. Izvestiya Volgogradskogo gosudarstvennogo pedagogicheskogo universiteta [Bulletin of the Volgograd State Pedagogical University], 2013, no. 8 (83), pp. 47-53.

22. Pererva E.V., Dyachenko A.N. Marker stressa ili migratsiy (k voprosu ob interpretatsii ekzostoza slukhovogo prokhoda na kostnykh materialakh naseleniya epokhi sredney bronzy iz mogilnikov Nizhnego Povolzhya) [A Stress or Migration Marker (A Study of the Auditory Canal Exostosis in the Skeleton Material of the Middle Bronze Age Population from the Lower Volga Region Burial Grounds)]. Vestnik arkheologii, antropologii $i$ etnografii [Bulletin of Archaeology, Anthropology and Ethnography], 2017, iss. 4 (39), pp. 61-78.

23. Potekhina I.D. Zvidky pryjshly lyudy z vizkamy: antropologiya $\mathrm{j}$ arxeogenetyka yamnyh pohovan Sugoklejskogo kurganu [Where Did the People with the Carts Come From: The Anthropology and Archeogenetics of the Yamna Culture Graves of the Sugoklai Mound]. Olviyskyy forum (pamyati V.V. Krapivinoy) do 150-richchya doslidzhennya Olviyi: Materialy II mizhnarodnoy konferentsiyi (Mykolayiv, 4-5 travnya 2018 roku) [Olvia Forum (In Memory of V.V. Krapivina) to the $150^{\text {th }}$ Anniversary of Olbias Study. Proceedings of the $2^{\text {nd }}$ International Conference (Mykolayiv, May 4-6, 2018)], Mykolayiv, Lukomore Publ., 2018, pp. 32-34.

24. Potekhina I.D. Nosiyi yamnoyi kultury Sugoklejskogo kurganu za danymy kraniologiyi i arxeogenetyky $\mathrm{v}$ antropologichnomu konteksti Pivnichnopontijskogo region [Carriers of the Yamna Culture of the Sugogleja Mound After the Craniology and Archeogenetics in the Anthropological Context of the Northern Pontian Region]. Istorychna antropologiya ta bioarheologiya Ukrayiny [Historical Anthropology and Bioarchaeology of Ukraine], iss. 3. (to appear).

25. Razhev D.I., Rykun M.P., Svyatova E.O. Stomatologicheskoe zdorovye srednevekovogo naseleniya lesnoy zony Zapadnoy Sibiri [Stomatological Health od the Population of the Western Siberia Forest Zone]. Vestnik arkheologii, antropologii i etnografii [Bulletin of Archaeology, Anthropology and Ethnography], 2011, iss. 1 (14), pp. 103-115.

26. Svyatko S.V. Dieta naseleniya afanasyevskoy kultury po dannym izotopnogo analiza, analiza zubnykh patologiy i statisticheskogo analiza pogrebeniy [Diet of the Population of Afanasyev Culture According to Isotope Analysis, Analysis of Dental Pathologies and Statistical Analysis of Burials]. Stepanova N.F., Polyakov A.B., eds. Afanasevskiy sbornik [Afanasiev Collection]. Barnaul, Azbuka Publ., 2010, pp. 225-232.

27. Tur S.S. Zubnye markery paleodiety $\mathrm{v}$ kraniologicheskoy serii naseleniya afanasyevskoy kultury Altaya [Dental Markers of Paleo Diet in the Craniological Series of the Population of the Afanasiev Culture of Altai]. Stepanova N.F., Polyakov A.B., eds. Afanasevskiy sbornik [Afanasiev Collection]. Barnaul, Azbuka Publ., 2010, pp. 251-258

28. Tur S.S., Rykun M.P. Kraniologicheskie materialy afanasevskoy kultury Gornogo Altaya v paleoekologicheskom aspekte issledovaniya [The Craniological Materials of the Afanasyev Culture of Gorny Altai in the Paleoecological Aspect of the Study]. Vestnik antropologii [Bulletin of Anthropology], 2006, no. 14, pp. 102-108.

29. Tur S.S., Rykun M.P. Naselenye andronovskoy kultury Altaya po dannym bioarkheologycheskogo issledovaniya [The Population of the Andronovo Culture of Altai According to Bioarchaeologic Research]. Izvestiya altayskogo gosudarstvennogo universiteta [Bulletin of Altai State University], 2008, no. 4-2, pp. 191-198.

30. Ushkova Yu., Kozak O. Travmy ta trepanatsii na cherepakh z pokhovan yamnoi kulturno-istorychnoi spilnosti [Traumas and Trepanations on Skulls from the Yamna Cultural and Historical Community]. Mahisterium [Magisterium], 2011, no. 45 (Arkheolohichni studii) [Archaeological Research], pp. 29-34.

31. Yanish E. Osteolohichni materialy z pokhovan yamnoyi i babynskoyi kultur Suhokleyskoyi mohyly [Osteological Materials on the Burial Grounds of the Pit and Babin Cultures of the Sugoglai Tomb]. Istorychna antropolohiya ta bioarkheolohiya 
Ukrayiny [Historical Anthropology and Bioarchaeology of Ukraine], no. 2-3. (In press).

32. Velasco-Vazquez J., Betancor-Rodriguez A., Arnay-De-La Rosa M., Gonzalez-Reimers E. Auricular Exostoses in the Prehistoric Population of Gran Canaria. American Journal of Physical Anthropology, 2000, vol. 112 (1), pp. 49-55.

33. Barnes E.J. Developmental Defects of the Axial Skeleton in Paleopathology. Niwot, University Press of Colorado, 1994. 360 p.

34. Boocock P., Roberts Ch., Manchester K. Maxillary Sinusitis in Medieval Chichester, England. American Journal of Physical Anthropology, 1995, vol. 98, pp. 483-495.

35. Breitinger E. Zur Berechnung der Körperhöhe aus dem langen Gliedmaßenknochen. Anthropologischer Anzeiger, 1938, Bd.14, S. 249-274.

36. Fabiani M., Barbara M., Filipo R. External Ear Canal Exostosis and Aquatic Sports. Journal for Otorhinolaryngology and Its Related Specialties, 1984, no. 46 (3), pp. 159-164. DOI: 10.1159/000275702.

37. Fuchs K., Berezina N., Gresky J. Malnutrition in the Bronze Age: Scurvy in Population of Northern Caucasus. Naseleniye yuga Rossii s drevneyshikh vremen do nashikh dney: materialy mezhdynarod. nauch. konf. [The Population of the South Russia from Ancient to Modern Times. Proceedings of the International Conference]. Rostov-on-Don, Izd-vo YuNTs RAN, 2013, pp. 54-56.

38. Giro C.M. Enamel Hypoplasia in Human Teeth: An Examination of Its Causes. Journal of the American Dental Association, 1947, no. 34 (5), pp. 310-317.

39. Gresky J., Berezina N. Oral Hygiene and Patterns of Dental Wear in Skeletons from Six Chalkolithic and Bronze Age Cemeteries in Northern Caucasus. Naselenie yuga Rossii s drevneyshikh vremen do nashikh dney: materialy mezhdynarodnoy nauchnoy konferentsii [The Population of the South Russia from Ancient to Modern Times]. Rostov-onDon, Izd-vo YuNTs RAN, 2013, p. 33.

40. Kennedy G.E. The Relationship Between Exostoses and Cold Water: A Latitudinal Analysis. American Journal of Physical Anthropology, 1986, vol. 71 (4), pp. 401-415. DOI:10.1002/ajpa.1330710403.

41. Koel K. Paläopathologische und Bioarchäologische Untersuchungen an den Frühbronzezeitlichen Skeletfunden der Erwachsenenpopulation von Jelšovce (Slowakische Republik). Ein Beitrag zur Rekonstruktion des Gesundheitsstatus Frühbronzezeitlicher Populationen. Diss. Naturwiss, Universität Hildesheim, 2011. $386 \mathrm{~S}$.

42. Merrett D., Pfeiffer S. Maxillary Sinusitis as an Indicator of Respiratory Health in Past Population. American Journal of Physical Anthropology, 2000, vol. 111,pp. 310-318.
43. Molnar S. Human Tooth Wear, Tooth Function and Cultural Variability. American Journal of Physical Anthropology, 1971, vol. 34 (2), pp. 175189. DOI:10.1002/ajpa.1330340204.

44. Nikolova A.V., Keiser E. Die Absolute Chronologie der Jamnaja-Kultur im Nördlichen Schwarzmeergebiet auf der Grundlage erster dendrologischer Daten. Eurasia Antiqua, 2009, Bd. 15, S. $209-240$.

45. Okumura M.M.M., Boyadjian C.H.C., Eggers S. Auditory Exostoses as an Aquatic Activity Marker: A Comparison of Coastal and Inland Skeletal Remains from Tropical and Subtropical Regions of Brazil. American Journal of Physical Anthropology, 2007, vol.132, pp. 558-567. DOI:10.1002/ajpa.20544.

46. Panhuysen R.G.A.M., Coenen V., Bruintjes T. Chronic Maxillary Sinusitis in Medieval Maastricht, the Netherlands. International Journal of Osteoarchaeology, 1997, vol. 7, pp. 610-614.

47. Pearson K. Mathematical Contributions to the Theory of Evolution. On the Reconstruction of the Stature of Prehistoric Races. Philosophical Transactions of the Royal Society London, 1899, no. 192, pp. 169-244.

48. Perizonius W.R.K., Pot T.J. Diachronic Dental Research on Human Skeletal Remains Excavated in the Netherlands. Dorestad Cemetery on "The Heul". Berichten van de Rijksdienst Voor het Oudheidkundig Bodemonderzoek, 1981, Bd. 31. 45 S.

49. Piontek J. Stress w Populacjach Pradziejowych: Zalozenia, Metody i Wstepne Wyniki Badan. Rożnowski F., ed. Biologia populacji ludzkich wspolczesnych i pradziejowych . Siupsk, WSP, 1992, S. 321-345.

50. Altuna Mariezkurrena X., Suárez J.G., Albisua I.L., Vea Orte J.C., Guimerá J.Al. Prevalence of Exostoses Surfers of the Basque Coast. Acta Otorrinolaringol Espaniol, 2004, vol. 55. pp. 364-368. DOI: 10.1016/S0001-6519(04)78537-4.

51. Roberts Ch.À., Buikstra J. The Bioarchaeology of Tuberculosis: A Global View on a Reemerging Diseases. Florida, University Press, 2003. 368 p.

52. Schultz M. Paläopathologische Diagnostik. Knussmann R., Hrsg. Anthropologie: Handbuch der Vergleichenden Biologie des Menschen. Bd. 1 (1), Wesen und Methoden der Anthropologie. Stuttgart, Fischer Verlag, 1988, S. 480-496.

53. Schultz M., Archäologische Skelettfunde als Spiegel der Lebensbedingungen früher Viehzüchter und Nomaden in der Ukraine. Tolochko P.P., Murzin V.Ju., hrgb. Gold der Steppe. Archaeologie der Ukraine. Kiev, Schlezvig, 1991, pp. 27-42

54. Schultz M. Spuren Unspezifischer Entzündungen an Prähistorischen und Historischen Schädeln. Kaufmann B., Hrsg. Anthropologische Beiträge 4A, 84 pp und 4B. AeschBL, Anthropologisches 


\section{БИОАРХЕОЛОГИЯ ДРЕВНИХ И СРЕДНЕВЕКОВЫХ ПОПУЛЯЦИЙ}

Forschungsinstitut Aesch und Anthropologische Gesellschaft in Basel 1993. 84 S.

55. Schultz M. The Role of Tuberculosis in Infancy and Childhood in Prehistoric and Historic Population. Pálfi G., Dutour O., Deák J., Hutás I., eds. Tuberculosis. Past and Present. Budapest, GBTB Foundation, 1999, pp. 503-507.

56. Schultz M. Paleohistopathology of Bone:A New Approach to the Study of Ancient Diseases. Yearbook of Physical Anthropology, 2001, vol. 44, pp. 106-147.

57. Schultz M., Schmidt-Schultz T.H. The Role of Deficiency Diseases in Infancy and Childhood of Bronze Age Population. Milano L., Bertoldi F., Canei A., eds. Palaeonutrition and Food Practices in the Ancient Near East. Venezia, 2008, pp. 1-18.

58. Smith B.H. Patterns of Molar Wear in HunterGatherers and Agriculturalists. American Journal of Physical Anthropology, 1984, vol. 63, pp. 39-56.

59. Spekker O., Hunt D.R., Paja L., Molnár E., Pálfi G., Schultz M. Tracking Down the White Plague: The Skeletal Evidence of Tuberculous Meningitis in the Robert J. Terry Anatomical Skeletal Collection. PLOS ONE, 2020. DOI: 10.1371/journal.pone.0230418 (Accessed 23 March 2020).

60. Trotter M. Estimation of Stature from Intact Long Limb Bones. Stewart T.D., ed. Personal Identification in Mass Disasters. Washington, Smithsonian Press, 1970, pp. 85-97.

61. Turner II C.G., Cadien J.D. Dental Chipping in Aleutes, Eskimos and Indians. American Journal of Physical Anthropology, 1969, vol. 31, pp. 303-210.

62. Ubelaker D.H., Phenice T.W., Bass W.M. Artificial Interproximal Grooving of the Teeth in American Indians. American Journal of Physical Anthropology, 1969, vol. 30 (1), pp. 145-149.

63. Ullrich H. Neue Ergebnisse zur Frage nach der Verwandtschaftlichen Beziehungen der mitteldeutschen, böhmischen und mährischen
Aunjetitze. Anthropos (Akta Anthropologického kongresu, Mikulov, 1961), 1963, Bd. 1-5, S. 271-274.

64. Ullrich H. Das Aunjetitzer Gräberfeld von Grossbrembach. Teil 1: Anthropologische Untersuchungen zur Frage nach Entstehung und Verwandtschaft der thüringischen, böhmischen und mährischen Aunjetitzer. Weimar, Beier \& Beran, 1972. $170 \mathrm{~S}$.

65. Villotte S., Stefanović S., Knüsel Ch.J. External Auditory Exostoses and Aquatic Activities During the Mesolithic and the Neolithic in Europe: Results from a Large Prehistoric Sample. Anthropologie, 2014, vol. LII/1, pp.73-89.

66. Villotte S., Küüsel Ch.J. External Auditory Exostoses and Prehistoric Aquatic Resource Procurement. Journal of Archaeological Science, 2016, vol. 6, pp. 633-636. DOI: 10.1016/j.jasrep. 2015.05.013.

67. Walker P.L., Bathurst R.R., Rickman R., Gjerdrum T., Andrushko V.A. The Causes of Porotic Hyperostosis and Cribra Orbitalia: A Reappraisal of the Iron-Deficiency-Anemia Hypothesis. American Journal of Physical Anthropology, 2009, vol. 139 (2), pp. 109-125.

68. Wells C. Bones, Bodies, and Disease. Evidence of Disease and Abnormality in Early Man. New York, Frederick A. Praeger, 1964. 288 p.

69. Wurm H. Über die Schwankungen der durchschnittlichen Körperhöhe im Verlauf der deutschen Geschichte und die Einflüsse des Eiweißanteiles der Kost. Homo, 1982, Bd. 33, S. 21-42.

70. Wurm H. Konstituzion und Ernährung II: Zum Einfluß von Ernährung, insbesondere zum Einfluß von Nahrungseiweiß unterschiedlicher Quantität und Qualität auf die Konstitution nach Ernährungsversuchen - Ein Vorbericht. Homo, 1987, Bd. 38, S. 34-58.

71. Živanoviè S. Ancient Diseases. The Elements of Palaeopathology. London, Methuen, 1982. 285 p.

\section{Information About the Author}

Aleksandra D. Kozak, Candidate of Sciences (History), Senior Researcher, Bioarchaeology Department, Institute of Archaeology National Academy of Science of Ukraine, Prosp. Geroiv Stalingrada, 12, 04211 Kyiv, Ukraine, akozak26@ukr.net, https://orcid.org/0000-0003-2094-4490

\section{Информация об авторе}

Александра Денисовна Козак, кандидат исторических наук, старший научный сотрудник отдела биоархеологии, Институт археологии Национальной академии наук Украины, просп. Героев Сталинграда, 12, 04211 г. Киев, Украина, akozak26@ukr.net, https://orcid.org/0000-0003-2094-4490 